\title{
Photosynthesis in reciprocal grafts of drought-tolerant and drought-sensitive cultivars of soybean under water stress
}

\author{
S.Y. LI",**, W.B. WANG*, X.D. YAO**, C.L. WANG*, Y.Q. CAO*, L.J. ZHANG*, H.J. ZHANG*, \\ F.T. XIE*,+, and S.H. SONG*,+ \\ Institute of Crop Research, Liaoning Academy of Agricultural Sciences, 110161 Shenyang, China* \\ Soybean Research Institute, Shenyang Agricultural University, 110161 Shenyang, China**
}

\begin{abstract}
Maintaining greater photosynthetic performance is important to improve drought resistance in soybean. However, photosynthetic response mechanisms to drought via the interaction between root and shoot remain to be clarified. Here, we investigated the roles of roots and shoots in photosynthetic responses to water stress. Grafted plants of drought-tolerant cultivar L14 and drought-sensitive cultivar L21 were grown in the pot-culture experiments. Some photosynthetic and physiological traits were measured after water-stress treatments during a podding stage. The L14 as rootstock showed a stronger growth vigor under water stress, leading to increases in some photosynthetic traits. Although the photosynthesis of L21 scion was improved by grafting onto L14 rootstock, it was still lower than that of L14 scion. This indicated that not only the greater water absorption capacity via roots but also the physiological property of leaves conferred a higher photosynthetic capacity and drought resistance in soybean.
\end{abstract}

Additional key words: carboxylation efficiency; chlorophyll fluorescence; gas exchange; water status.

\section{Introduction}

Climatic changes with persistent water deficiency occur around numerous parts of the world, which is considered to be a major limiting factor in crop production worldwide (Shao et al. 2009). In soybean (Glycine max), a reduction of grain yield is maximal when water deficiency happens during flowering and podding stage, which causes a decrease in a pod number per plant (Kokubun et al. 2001). After anthesis, drought-induced lower photosynthetic capacity increased the rate of pod abortion in soybean, as a result of carbohydrate deprivation (Liu et al. 2004). Therefore, maintaining the greater capacity of photosynthesis and assimilate supply might be important to improve drought resistance in soybean.

Physiological responses in leaves to water stress included conservation of soil water by the decline of water loss, radiation absorption, and relative water content (Xoconostle-Cazares et al. 2010). Drought-induced lower leaf water potential led to decline in the photosynthetic rate $\left(P_{\mathrm{N}}\right)$, stomatal conductance $\left(g_{\mathrm{s}}\right)$, and transpiration rate (E) of soybean (Ohashi et al. 2006, Zhang et al. 2008). In response of leaves to water deficit, stomatal closure declines intercellular $\mathrm{CO}_{2}$ concentration $\left(C_{\mathrm{i}}\right)$ which restrains $\mathrm{CO}_{2}$ assimilation and results in an imbalance between electron requirement and photochemical activity at PSII (He et al. 1995, Flagella et al. 1998). Consequently, absorbed energy may exceed that required to generate NADPH and ATP for carbon fixation, which may result in photodamage (Kao and Tsai 1998).

The cultivars were empirically categorized as tolerant and sensitive to water stress on the basis of their capacity to maintain relative water content and sustained growth at decreased soil moisture conditions. Previous studies have found critical differences in photosynthetic responses to water stress between drought-sensitive and droughttolerant genotypes (Fenta et al. 2012, Ries et al. 2012). The stability of photosynthesis under water deficit is also considered to be a crucial aspect of drought tolerance in soybean (Gilbert et al. 2011). In addition, the $P_{\mathrm{N}}$ of leaves is also closely related to the status of other tissues, such as root system. Developed roots, having a higher total surface area, enhance moisture and nutrient extraction in order to maintain $P_{\mathrm{N}}$ under drought conditions (Blum 2011, Comas et al. 2013). Root growth also affected the water absorption capacity of plants. The xylem sap is resulting

Received 13 April 2019, accepted 8 July 2019.

${ }^{+}$Corresponding author; phone: +86-24-88487135, fax: +86-24-88487135, e-mail: xft299@sina.com (F.T. Xie);

phone: +86-24-31029887, fax: +86-24-31029887, e-mail: songshuhong2017@126.com (S.H. Song)

Abbreviations: $\mathrm{CE}$ - initial carboxylation efficiency; $C_{\mathrm{i}}$ - intercellular $\mathrm{CO}_{2}$ concentration; ETR - electron transport rate; $g_{\mathrm{s}}-$ stomatal conductance; LRWC - leaf relative water content; NPQ - nonphotochemical quenching; $P_{\max }$ - photosynthetic capacity; $P_{\mathrm{N}}-$ photosynthetic rate; $\mathrm{q}_{\mathrm{p}}$ - photochemical quenching; RBSM - root bleeding sap mass; $R_{\mathrm{p}}$ - rate of respiration in the presence of light; $\mathrm{Y}_{(\mathrm{II})}$ - the actual photochemical efficiency of PSII.

Acknowledgments: This study was supported by the China Postdoctoral Science Foundation Grant (No. 2017 M621157), Modern Agricultural Industry Technology System (CARS-04-CES12), and National Key R\&D Program of China (No. 2016YFD0100201-01). S.Y. Li and W.B. Wang contributed equally to the work. 
from root pressure and might mediate exchanges between shoots and roots (Li et al. 2009). The root bleeding sap mass (RBSM) was used as an indicator of the root growth vigor in previous study and had positive relationship with $P_{\mathrm{N}}$ in soybean (Cui et al. 2016). However, it remained to be clarified whether a relatively high photosynthesis of drought-resistant soybean under water stress is typical only for leaves or for the root system or for the whole plant.

The soybean cultivars Liaodou 14 (L14) and Liaodou 21 (L21) were categorized as drought-tolerant and droughtsensitive, respectively, based on their ability to maintain biomass and grain yield under drought conditions (Yan et al. 2018). In the practice, we found that the leaves of L14 had higher $P_{\mathrm{N}}$ than those of L21, especially under water stress conditions. We hypothesized that the greater $P_{\mathrm{N}}$ in the drought-tolerant soybean cultivar L14 was not only attributed to the photosynthetic advantage of leaves, but also due to the effect of stronger root growth vigor under water deficit. Grafting in order to connect a scion and rootstock of differing soybean genotypes has been used in our previous studies (Li et al. 2017a,b; 2019), which could be helpful to test this hypothesis. In the present study, L14 and L21 were used in the reciprocal grafting experiment to determine the shoot and root effects on leaf photosynthesis under well-watered and water-stress conditions. The results would provide the breeding strategies via root-shoot interaction to improve the drought-resistance in soybean.

\section{Materials and methods}

Plant material and grafting procedure: Two soybean (Glycine max) cultivars, L14 and L21, were released from Liaoning Academy of Agricultural Sciences and exhibited differing tolerance to drought stress for grain yield (Fig. 1S). The drought-tolerant cultivar L14 and drought-sensitive cultivar L21 were used as scion and rootstock in the reciprocal grafts. The above cultivars tested were of the maturity group III. Selected soybean seeds were planted in plastic pots $(12 \times 12 \times 12 \mathrm{~cm})$ with soil. Grafting was initiated at the cotyledon stage (VC), and the procedure was described in Pantalone et al. (1999). Six grafting treatments included rooted (non-grafted) L14, rooted (nongrafted) L21, and grafted scion/rootstock combinations: L14/L14, L21/L21, L14/L21, and L21/L14. Immediately after grafting, the rooted and grafted plants were placed in a glasshouse under the seedling management described in the previous study (Li et al. 2017a).

The pot-culture experiments were carried out under open field conditions in 2017 and 2018 at Liaoning Academy of Agricultural Sciences $\left(41^{\circ} 83^{\prime} \mathrm{N}, 123^{\circ} 56^{\prime} \mathrm{E}\right)$, Liaoning Province, China. After seedling recovery, the surviving grafts (survival rate $\geq 90 \%$ ) and non-grafts were transplanted into the pots $(30 \times 30 \times 25 \mathrm{~cm}, 15.0 \mathrm{~kg}$ of soil $)$. The soil was brown loam developed in loess parent material, which was derived from the $0-20 \mathrm{~cm}$ surface layer of field and sieved out. The particle size distribution was: clay grain $(<0.002 \mathrm{~mm})$ of $23.3 \%$, silt grain $(0.002$ $-0.02 \mathrm{~mm})$ of $36.3 \%$, and sand grain $(>0.02 \mathrm{~mm})$ of $40.5 \%$. The soil bulk density was $1.12 \mathrm{~g} \mathrm{~cm}^{-3}$. The field water-holding capacity was $26.5 \%$, which was measured from above layer by gravimetric method. Chemical characteristics of soil were: soil organic matter of $22.30 \mathrm{~g} \mathrm{~kg}^{-1}$, total nitrogen of $1.91 \mathrm{~g} \mathrm{~kg}^{-1}$, available nitrogen of $0.09 \mathrm{~g} \mathrm{~kg}^{-1}$, available phosphorus of $0.01 \mathrm{~g} \mathrm{~kg}^{-1}$, available potassium of $0.11 \mathrm{~g} \mathrm{~kg}^{-1}$, and $\mathrm{pH}$ of 6.8 in distilled water $(1: 5, \mathrm{v} / \mathrm{v})$. The water-stress treatments began about $80 \mathrm{~d}$ after germination (podding stage) and were maintained during 10-12 d. The well-watered treatment maintained the soil moisture content at $80 \%$ of the field water-holding capacity, whereas water stress corresponded to $50 \%$. The water content of soil was measured by a weighing method every day and replenished by water to the set value. There was a randomized complete block design with six replications (pots), and each pot contained two plants.

Gas-exchange parameters: After water-stress treatment, the upper third leaf was used to measure the gas-exchange parameters by the $L I-6400$ portable photosynthesis system (LI-6400, Li-Cor, Lincoln, NE). The light intensity was set at a PPFD of $1,200 \mu \mathrm{mol} \mathrm{m} \mathrm{m}^{-2} \mathrm{~s}^{-1}$. The leaf temperature was kept at $25-30^{\circ} \mathrm{C}$, relative humidity was $60-65 \%, \mathrm{CO}_{2}$ concentration of $380 \mu \mathrm{mol}\left(\mathrm{CO}_{2}\right) \mathrm{mol}^{-1}$, and air flow of $500 \mu \mathrm{mol} \mathrm{s}{ }^{-1}$. Six plants from six pots $(n=6)$ were measured in the morning on a sunny day.

$\boldsymbol{P}_{\mathrm{N}} / \boldsymbol{C}_{\mathrm{i}}$-response curves were also measured on six plants from six pots $(n=6)$. Cuvette conditions were maintained at a PPFD of $1,200 \mu \mathrm{mol} \mathrm{m} \mathrm{m}^{-2} \mathrm{~s}^{-1}$, relative humidity of $60-65 \%$, and a leaf temperature of $25-30^{\circ} \mathrm{C}$. $\mathrm{A} \mathrm{CO}_{2}$ mixer was used to control the ambient $\mathrm{CO}_{2}$ concentration in the cuvette across the series of 50, 100, 200, 400, 500, 600, 700, and $800 \mu \mathrm{mol}\left(\mathrm{CO}_{2}\right) \mathrm{mol}^{-1}$. The $P_{\mathrm{N}}$ and $C_{\mathrm{i}}$ were recorded after equilibration to a steady state. Nonlinear regression, based on the equations of Cai and $\mathrm{Xu}$ (2000), was used to estimate the CE (initial carboxylation efficiency), $P_{\max }$ (photosynthetic capacity), and $R_{\mathrm{p}}$ (rate of respiration in the presence of light) for each $P_{\mathrm{N}} / C_{\mathrm{i}}$ curve. The equations were represented as $P_{\mathrm{N}}=\mathrm{CE} \times P_{\max } \times C_{\mathrm{i}} /\left(\mathrm{CE} \times C_{\mathrm{i}}+P_{\max }\right)-R_{\mathrm{p}}$.

Chlorophyll (Chl) fluorescence parameters were measured on six plants from six pots $(n=6)$ by $P A M-2500$ chlorophyll fluorometer (Heinz Walz $\mathrm{GmbH}$, Germany). Following 30-min-dark adaptation for upper third leaves, the minimum fluorescence value was determined, and the maximum fluorescence was recorded using a 0.8 -s saturation pulse at 3,000 $\mu \mathrm{mol}$ (photon) $\mathrm{m}^{-2} \mathrm{~s}^{-1}$. Then the actinic white light $\left[1,000 \mu \mathrm{mol}\left(\right.\right.$ photon) $\left.\mathrm{m}^{-2} \mathrm{~s}^{-1} \mathrm{PAR}\right]$ was switched on for $5 \mathrm{~min}$. During the process, the light-adapted maximal fluorescence yield and minimal fluorescence at the light-adapted state was recorded. Then the actual photochemical efficiency of PSII [Y $\left.\mathrm{Y}_{(\mathrm{II})}\right]$, electron transport rate $(\mathrm{ETR})$, photochemical quenching $\left(\mathrm{q}_{\mathrm{P}}\right)$, and nonphotochemical quenching (NPQ) were calculated by the PamWin V3.12g (control and data aquisition system).

Rubisco activity assay: The upper third leaves were collected into liquid nitrogen immediately and stored at $-80^{\circ} \mathrm{C}$ for Rubisco activity assay. Leaf samples of approx. $0.5 \mathrm{~g}$ fresh mass (FM) were extracted with $2 \mathrm{~mL}$ of 
enzyme extraction buffer [20\% (v/v) glycerol, 1\% (v/v) Triton-X100 (Sigma, St. Louis, MO, USA), 0.25\% (w/v) bovine serum albumin, $50 \mathrm{mM}$ HEPES/KOH $\mathrm{pH} 7.5$, $1 \mathrm{mM}$ EDTA, $10 \mathrm{mM} \mathrm{MgCl} 2,1 \mathrm{mM}$ PMSF, and $0.5 \mathrm{mM}$ DTT]. The initial and total activity of Rubisco (ribulose1,5-bisphosphate carboxylase/oxygenase, EC 4.1.1.39) was determined with three replications per sample by microplate reader (Varioskan Flash, Thermo Fisher Scientific, Inc., Waltham, MA, USA) using a rapid, nonradioactive microplate-based method (Sulpice et al. 2007). The initial activity was divided by the total activity to determine the Rubisco activation state.

Root bleeding sap: To reveal the growth vigor of L14 and L21 rootstocks, the RBSM was measured in six pots $(n=6)$ under well-watered and water stress conditions. To collect the root bleeding sap samples, the shoots were cut just under the cotyledons node of two plants from each pot with a very sharp cutter as described by Peoples et al. (1989).

Leaf water status: All leaves of two plants from each pot were collected to measure the leaf fresh mass (FM). Then the leaves were immersed in water for $4 \mathrm{~h}$ at room temperature (approximately $28^{\circ} \mathrm{C}$ ) to measure the turgid mass (TM). Finally, the leaves were oven dried at $105^{\circ} \mathrm{C}$ for $30 \mathrm{~min}$ and then at $85^{\circ} \mathrm{C}$ until constant mass to measure the dry mass (DM). The leaf relative water content (LRWC) was determined according to the following equation: $\mathrm{LRWC}=(\mathrm{FM}-\mathrm{DM}) /(\mathrm{TM}-\mathrm{DM})$.

Statistical analysis: Data analysis was conducted with an analysis of variance (ANOVA) in general linear model by SPSS 19.0 (SPSS, Inc., Chicago. USA). Genotype (grafting treatments), water-stress treatment, and genotype $\times$ waterstress treatment were as fixed effects. Years, along with the genotype $\times$ year, water-stress treatment $\times$ year, and genotype $\times$ water-stress treatment $\times$ year were regarded as a random factor. Means were subjected to the least significant difference $(L S D)$ test at the $P<0.05$ level.

\section{Results}

The grafting procedure per se had no effect on photosynthetic traits. Non-grafted L14 vs. self-grafted L14 and non-grafted L21 vs. self-grafted L21 had insignificant differences in most photosynthetic traits in the ANOVA. A comparison of reciprocal grafts was undertaken to determine the effect of roots and shoots on photosynthesis under well-watered and water-stress conditions.

Water status: Under the water stress imposed, the RBSM decreased significantly (Fig. 1A). The reduction of RBSM followed the order L14/L14 (36\%) $\leq$ L21/L14 (38\%) < L21/L21 $(55 \%) \leq$ L14/L21 (56\%). With the same scion genotype, compared to L21 rootstock, the L14 as rootstock showed the increases of 12.8 and $60.8 \%$ in RBSM under well-watered and water-stress conditions, respectively. In contrast, with the same rootstock genotype, insignificant difference in RBSM was observed between scions under either well-watered or water-stress conditions.
The LRWC also decreased significantly by water stress (Fig. 1B). The reduction of LRWC followed the order L14/L14 (14\%) $\leq$ L21/L14 (15\%) < L21/L21 (24\%) $\leq$ L14/L21 (25\%). With the same scion genotype, compared to $\mathrm{L} 21$ rootstock, the L14 as rootstock showed insignificant change in LRWC under well-watered condition, but the average increase of $16 \%$ under water-stress conditions. In contrast, with the same rootstock genotype, insignificant difference in LRWC was observed between scions under either well-watered or water-stress conditions.

Gas-exchange parameters: Water stress caused the decrease in $P_{\mathrm{N}}$ of leaves (Fig. $2 A$ ). The reduction of $P_{\mathrm{N}}$ followed the order L14/L14 (13\%) < L14/L21 (22\%) < L21/L14 $(22 \%)<$ L21/L21 (29\%). With the same scion genotype, compared to $\mathrm{L} 21$ rootstock, the L14 as rootstock showed insignificant change in $P_{\mathrm{N}}$ under well-watered conditions, but average increase of $12 \%$ under water-stress conditions. However, the L21 scion had always lower $P_{\mathrm{N}}$ than that of the L14 scion under both well-watered and water-stress conditions, even when grafted onto the L14 rootstock. Compared to the L21 scion, the L14 as scion showed a significant increase of $10 \%$ in $P_{\mathrm{N}}$ under wellwatered conditions and of $22 \%$ under water-stress conditions, while grafted onto the same rootstock genotype.

Under the water stress imposed, the reduction of $g_{\mathrm{s}}$ followed the order L21/L14 (30\%) < L14/L14 (40\%) < L21/L21 (45\%) < L14/L21 (54\%) (Fig. 2B). With the same

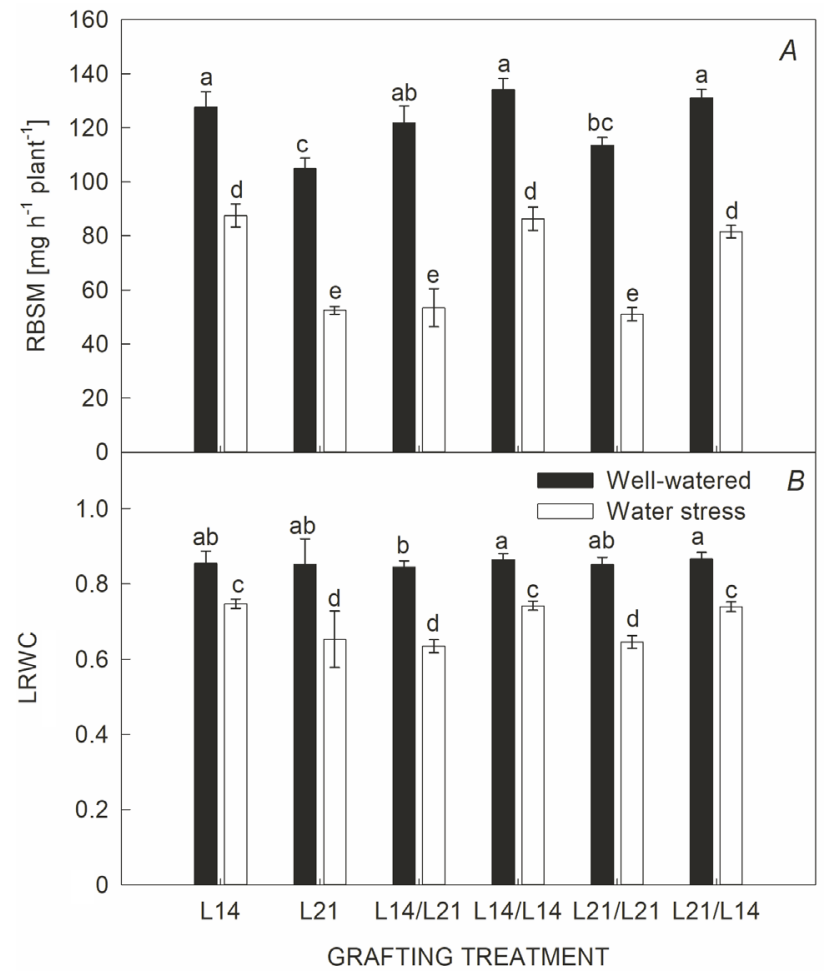

Fig. 1. Influence of water stress on root bleeding sap mass (RBSM) $(A)$ and leaf relative water content (LRWC) $(B)$ in different grafted soybean plants. Values are means $\pm \operatorname{SD}(n=12)$. Different letters following the mean values indicate significant differences between genotype $\times$ treatment at $P<0.05$ by $L S D$ test. 


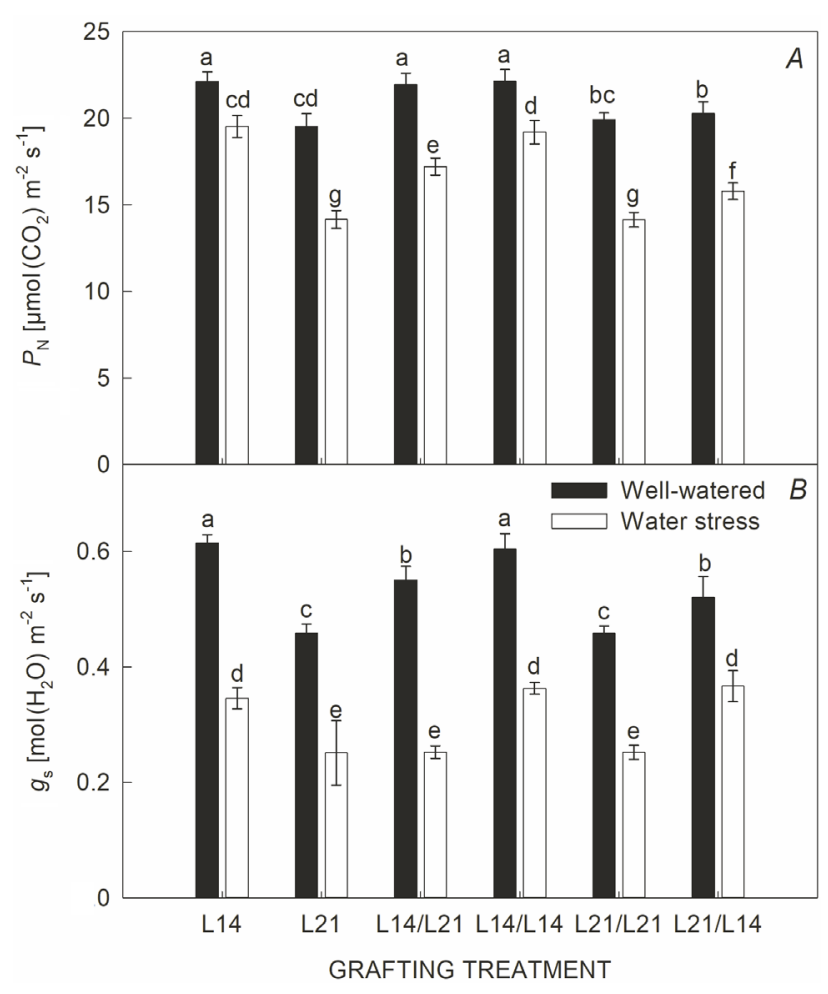

Fig. 2. Influence of water stress on the net photosynthetic rate $\left(P_{\mathrm{N}}\right)(A)$ and stomatal conductance $\left(g_{\mathrm{s}}\right)(B)$ in different grafted soybean plants. Values are mean $\pm \mathrm{SD}(n=12)$. Different letters following the mean values indicate significant differences between genotype $\times$ treatment at $P<0.05$ by $L S D$ test.

scion genotype, the L14 as rootstock had a lower stomatal sensitivity than that of the L21 rootstock in response to water stress, as apparent from the lesser reduction in $g_{\mathrm{s}}$. Compared to L21 rootstock, the L14 as rootstock exhibited the increase of 12 and $45 \%$ in $g_{\text {s }}$ under well-watered and water-stress conditions, respectively. In contrast, with the same rootstock genotype, the L14 scion showed the higher stomatal sensitivity than that of the L21 scion in response to water stress, as evidenced by the larger reduction in $g_{\mathrm{s}}$. Compared to L21 scion, the L14 as scion showed $18 \%$ higher $g_{\mathrm{s}}$ under well-watered condition, but the insignificant change under water-stress conditions.

Carboxylation efficiency: The $P_{\mathrm{N}} / C_{\mathrm{i}}$ curves were fitted to calculate the $\mathrm{CE}$ under well-watered and water-stress conditions (Fig. 3, Table 1S). The $P_{\mathrm{N}}$ decreased by water stress, especially under high $C_{\mathrm{i}}$ conditions, resulting from a reduction in $\mathrm{CE}$. The reduction of $\mathrm{CE}$ followed the order: L14/L14 (2\%) < L14/L21 (10\%) < L21/L14 (16\%) < L21/L21 (22\%). Rubisco enzyme activity assay showed the similar order: L14/L14 < L14/L21 < L21/L14 < L21/L21 for the reduction of initial Rubisco activity, total Rubisco activity, and Rubisco activation state by the water stress (Table 1). With the same scion genotype, compared to L21 rootstock, the L14 as rootstock exhibited the increase in initial Rubisco activity and Rubisco activation state by 11 and $10 \%$, respectively, under well-watered conditions, while by 12 and $7 \%$, respectively, under water-stress conditions. In contrast, with the same rootstock genotype, compared to L21 scion, the L14 as scion increased its initial Rubisco activity, total Rubisco activity, and Rubisco activation state by 26,7 , and $18 \%$, respectively, under wellwatered conditions, while by 51,8 , and $40 \%$, respectively, under water-stress conditions.

PSII of different grafts: Water stress increased the NPQ, but decreased the $\mathrm{Y}_{(\mathrm{II})}, \mathrm{q}_{\mathrm{P}}$, and ETR (Table 2). The increase of NPQ followed the order: L21/L14 (4\%) < L21/L21 (5\%) < L14/L14 $(12 \%)<$ L14/L21 (13\%); the reduction of $\mathrm{Y}_{(\mathrm{II})}$, $\mathrm{q}_{\mathrm{P}}$, and ETR followed the order: L14/L14 < L14/L21 < L21/L14 < L21/L21. With the same scion genotype, compared to L21 rootstock, the L14 as rootstock showed insignificant changes in $\mathrm{Y}_{(\mathrm{II})}, \mathrm{NPQ}, \mathrm{q}_{\mathrm{p}}$, and ETR under well-watered conditions, but increased by 20,15 , and $20 \%$, respectively, under water-stress conditions. In contrast, with the same rootstock genotype, compared to L21 scion, the L14 as scion increased $\mathrm{Y}_{(\mathrm{II})}, \mathrm{NPQ}, \mathrm{q}_{\mathrm{P}}$, and ETR by $14,15,15$, and $11 \%$, respectively, under well-watered conditions, while by $38,25,32$, and $37 \%$, respectively, under water stress conditions.

\section{Discussion}

Grafting has appeared to be a useful tool to quickly improve the drought resistance for modern vegetable production (Schwarz et al. 2010, Sánchez-Rodríguez et al. 2012, 2016; Kumar et al. 2017). In the present study, the reciprocal grafts of soybean cultivars differing in their water stress tolerance were used to determine the role of roots and shoots in photosynthetic responses to water stress, in order to provide the theoretical basis for droughtresistance breeding in soybean.

Roots are known to play an important role in plant tolerance to water deficit by controlling and adjusting the water supply to shoot transpiration demand (Marguerit et al. 2012). Many studies found a larger root system with greater mass at depth, larger xylem diameters or larger lateral root systems with more root hairs in drought-tolerant cultivars, which were more advantageous than droughtsensitive cultivars under drought conditions (Serraj et al. 1997, Fenta et al. 2014, Tanaka et al. 2014, Vadez 2014). The root architecture was not considered in this study because of the limited substrate volume in the pot-culture conditions. Some grafting experiments reported that the difference of root system abilities to maintain a leaf water status was mainly attributed to root hydraulic conductance but was not the effect of root mass (Sanders and Markhart 1992). The RBSM was used as a root vigor index in previous study to reflect a greater physiological function in L14 rootstock ( $\mathrm{Li}$ et al. 2017b). In present study, the L14 rootstock maintained its larger RBSM in the graft combination with L21 scion that normally confers lower RBSM, which resulted in higher LRWC under water stress. Interestingly, there was a lack of influence of the scion genotype on RBSM and LRWC, indicating that the roots rather than the shoots of L14 conferred the greater water absorption capacity and better water status under water stress. 


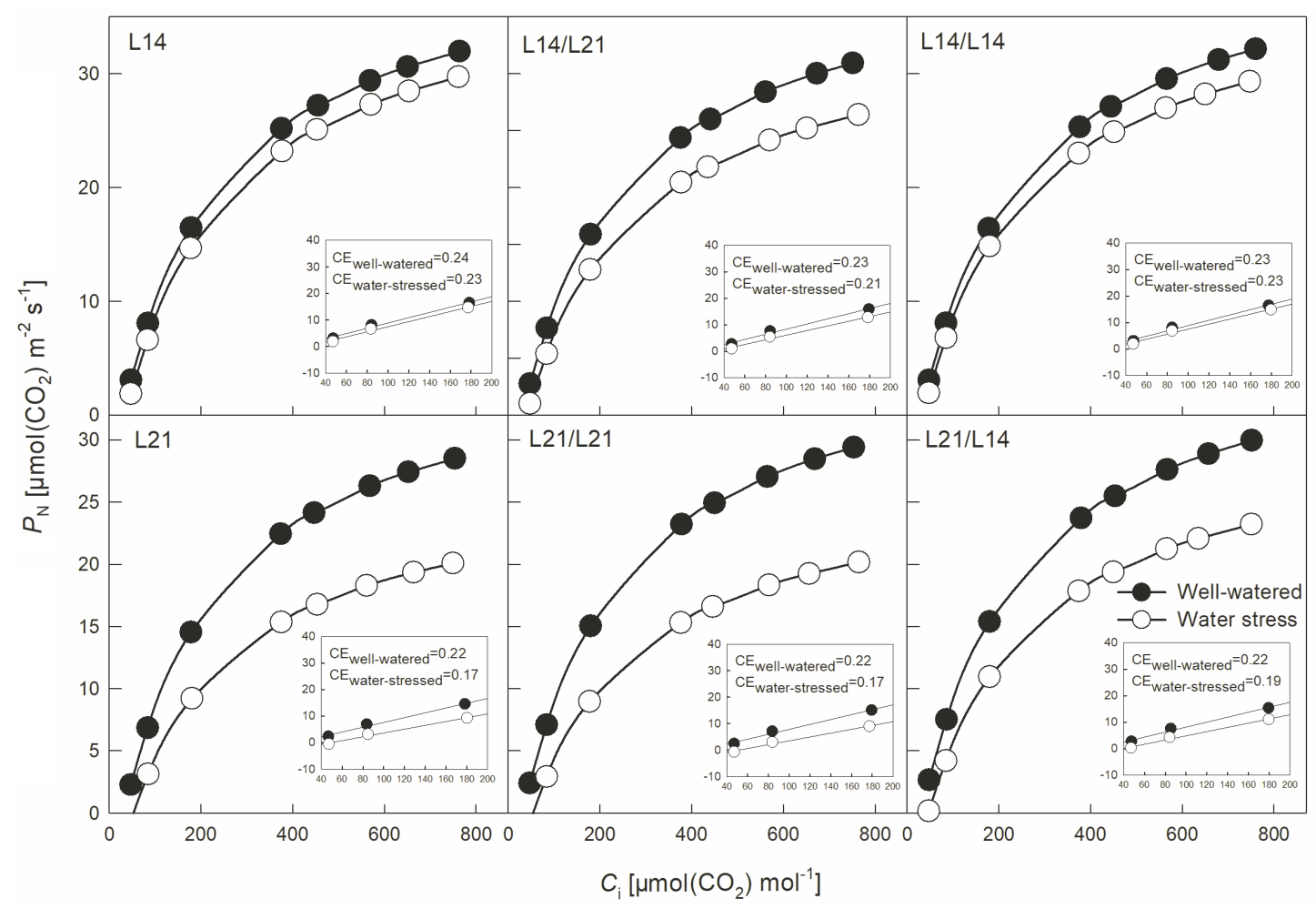

Fig. 3. Influence of water stress on $P_{\mathrm{N}} / C_{\mathrm{i}}$ response curves in different grafted soybean plants $(n=12)$. $C_{\mathrm{i}}-$ intercellular $\mathrm{CO}_{2}$ concentration; $P_{\mathrm{N}}-$ net photosynthetic rate.

Table 1. Influence of water stress on ribulose-1,5-bisphosphate carboxylase/oxygenase (Rubisco) activity in different grafted soybean plants. Values are means $\pm \operatorname{SD}(n=12)$. Different letters following the mean values indicate significant differences between genotype $\times$ treatment at $P<0.05$ by $L S D$ test.

\begin{tabular}{lllll}
\hline Genotype & Treatment & \multicolumn{2}{l}{ Rubisco activity $\begin{array}{c}\left.\text { [nmol(3-PGA) } \mathrm{g}^{-1}(\mathrm{FM}) \mathrm{min}^{-1}\right] \\
\text { Total }\end{array}$} & Rubisco activation state \\
\hline L14 & Well-watered & $3,646.17 \pm 155.6^{\mathrm{ab}}$ & $4,325.11 \pm 91.85^{\mathrm{a}}$ & $0.84 \pm 0.05^{\mathrm{ab}}$ \\
& Water stress & $3,124.99 \pm 137.41^{\mathrm{c}}$ & $4,172.89 \pm 87.20^{\mathrm{b}}$ & $0.75 \pm 0.04^{\mathrm{c}}$ \\
L21 & Well-watered & $2,725.65 \pm 183.09^{\mathrm{e}}$ & $3,934.59 \pm 91.66^{\mathrm{de}}$ & $0.69 \pm 0.06^{\mathrm{d}}$ \\
& Water stress & $1,847.76 \pm 62.77^{\mathrm{f}}$ & $3,451.38 \pm 94.39^{\mathrm{g}}$ & $0.54 \pm 0.03^{\mathrm{e}}$ \\
L14/L21 & Well-watered & $3,554.34 \pm 187.42^{\mathrm{b}}$ & $4,239.40 \pm 148.81^{\mathrm{ab}}$ & $0.84 \pm 0.06^{\mathrm{ab}}$ \\
& Water stress & $2,777.46 \pm 111.60^{\mathrm{d}}$ & $3,801.19 \pm 96.73^{\mathrm{e}}$ & $0.73 \pm 0.03^{\mathrm{cd}}$ \\
L14/L14 & Well-watered & $3,864.04 \pm 145.73^{\mathrm{a}}$ & $4,373.11 \pm 123.09^{\mathrm{a}}$ & $0.88 \pm 0.05^{\mathrm{a}}$ \\
& Water stress & $3,064.82 \pm 149.79^{\mathrm{c}}$ & $3,889.22 \pm 108.68^{\mathrm{de}}$ & $0.79 \pm 0.05^{\mathrm{bc}}$ \\
L21/L21 & Well-watered & $2,754.12 \pm 91.43^{\mathrm{e}}$ & $3,966.73 \pm 79.62^{\mathrm{cd}}$ & $0.69 \pm 0.03^{\mathrm{d}}$ \\
& Water stress & $1,818.54 \pm 91.58^{\mathrm{f}}$ & $3,469.09 \pm 113.10^{\mathrm{g}}$ & $0.52 \pm 0.04^{\mathrm{e}}$ \\
L21/L14 & Well-watered & $3,138.76 \pm 138.95^{\mathrm{c}}$ & $4,114.11 \pm 91.55 \mathrm{~b}^{\mathrm{c}}$ & $0.76 \pm 0.04^{\mathrm{c}}$ \\
& Water stress & $2,048.78 \pm 133.20^{\mathrm{f}}$ & $3,658.29 \pm 79.51^{\mathrm{f}}$ & $0.56 \pm 0.04^{\mathrm{e}}$ \\
\hline
\end{tabular}

The water status of plants under water deficit had a significant relationship with photosynthetic capacity (Mohsenzadeh et al. 2006, Rampino etal. 2006). Rootstockinduced increase in $P_{\mathrm{N}}$ under water stress was found in interspecific grafts (Nilsen et al. 2014, Liu et al. 2016). Grafting modern cultivars onto the L14 rootstock resulted in an increased $P_{\mathrm{N}}$ under well-watered conditions in our previous study (Li et al. 2017b). In present study, the $P_{\mathrm{N}}$ was increased by grafting onto the L14 rootstock under water stress, which was attributed to not only stomatal but also to nonstomatal factors. On the one hand, the $P_{\mathrm{N}}$ increased along with $g_{s}$, while the leaf water status under drought was improved by grafting on L14 rootstock. On the other hand, $P_{\mathrm{N}} / C_{\mathrm{i}}$ curve and Rubisco enzyme activity assay in this study showed an increased $\mathrm{CO}_{2}$ assimilation efficiency by grafting on the L14 rootstock under water stress. 
Table 2. Influence of water stress on chlorophyll fluorescence parameters in different grafted soybean plants. Values are means \pm SD $(n=12)$. Different letters following the mean values indicate significant differences between genotype $\times$ treatment at $P<0.05$ by $L S D$ test. ETR - electron transport rate; NPQ - nonphotochemical quenching; $\mathrm{q}_{\mathrm{p}}$ - photochemical quenching; $\mathrm{Y}_{\text {(II) }}$ - the actual photochemical efficiency of PSII.

\begin{tabular}{llllll}
\hline Genotype & Treatment & $\mathrm{Y}_{\text {(II) }}$ & NPQ & qP & ETR \\
\hline L14 & Well-watered & $0.25 \pm 0.01^{\mathrm{b}}$ & $1.79 \pm 0.10^{\mathrm{d}}$ & $0.43 \pm 0.02^{\mathrm{b}}$ & $85.75 \pm 3.69^{\mathrm{b}}$ \\
& Water stress & $0.19 \pm 0.02^{\mathrm{f}}$ & $1.99 \pm 0.10^{\mathrm{cd}}$ & $0.37 \pm 0.03^{\mathrm{e}}$ & $68.06 \pm 6.37^{\mathrm{f}}$ \\
L21 & Well-watered & $0.21 \pm 0.02^{\mathrm{b}}$ & $1.53 \pm 0.05^{\mathrm{cd}}$ & $0.38 \pm 0.05^{\mathrm{b}}$ & $78.15 \pm 8.22^{\mathrm{b}}$ \\
& Water stress & $0.12 \pm 0.02^{\mathrm{e}}$ & $1.60 \pm 0.06^{\mathrm{cd}}$ & $0.24 \pm 0.02^{\mathrm{d}}$ & $41.14 \pm 3.20^{\mathrm{e}}$ \\
L14/L21 & Well-watered & $0.25 \pm 0.02^{\mathrm{a}}$ & $1.75 \pm 0.07^{\mathrm{b}}$ & $0.42 \pm 0.01^{\mathrm{a}}$ & $87.14 \pm 6.87^{\mathrm{a}}$ \\
& Water stress & $0.17 \pm 0.02^{\mathrm{c}}$ & $1.98 \pm 0.08^{\mathrm{a}}$ & $0.32 \pm 0.02^{\mathrm{b}}$ & $58.93 \pm 6.34^{\mathrm{c}}$ \\
L14/L14 & Well-watered & $0.25 \pm 0.01^{\mathrm{b}}$ & $1.78 \pm 0.09^{\mathrm{cd}}$ & $0.43 \pm 0.02^{\mathrm{b}}$ & $88.08 \pm 3.43^{\mathrm{b}}$ \\
& Water stress & $0.19 \pm 0.01^{\mathrm{f}}$ & $1.99 \pm 0.19^{\mathrm{c}}$ & $0.37 \pm 0.02^{\mathrm{e}}$ & $67.98 \pm 6.14^{\mathrm{f}}$ \\
L21/L21 & Well-watered & $0.22 \pm 0.02^{\mathrm{a}}$ & $1.52 \pm 0.10^{\mathrm{b}}$ & $0.36 \pm 0.04^{\mathrm{a}}$ & $77.00 \pm 7.55^{\mathrm{a}}$ \\
& Water stress & $0.12 \pm 0.02^{\mathrm{d}}$ & $1.59 \pm 0.08^{\mathrm{a}}$ & $0.24 \pm 0.01^{\mathrm{c}}$ & $41.23 \pm 3.67^{\mathrm{d}}$ \\
L21/L14 & Well-watered & $0.23 \pm 0.01^{\mathrm{a}}$ & $1.54 \pm 0.06^{\mathrm{b}}$ & $0.38 \pm 0.05^{\mathrm{a}}$ & $80.43 \pm 6.18^{\mathrm{a}}$ \\
& Water stress & $0.15 \pm 0.03^{\mathrm{c}}$ & $1.59 \pm 0.08^{\mathrm{a}}$ & $0.28 \pm 0.01^{\mathrm{b}}$ & $51.73 \pm 2.54^{\mathrm{c}}$ \\
\hline
\end{tabular}

The L21 scion still had lower $P_{\mathrm{N}}$ than that of L14 scion, even if grafted onto the L14 rootstock. The greater $P_{\mathrm{N}}$ in the L14 scion was not due to the increased LRWC under well-watered or water-stress conditions, as evidenced by insignificant difference in LRWC between L14 scion and L21 scion grafted onto the consistent rootstock genotypes. In addition, there was the significant difference in $g_{\text {s }}$ between L14 scion and L21 scion under well-watered rather than under water-stress conditions. The pathways of water loss and $\mathrm{CO}_{2}$ absorption are diverse within the leaf, and their fluxes suffer from different restrictions, even though they are linked by the stomata (Egilla et al. 2005). The two processes could not be affected to the same degree by the stomatal closure. Soil drying induced the stomatal closure through root abscisic acid signal in order to reduce the water loss (Liu et al. 2003). Under water stress imposed, the leaves of L14 scion with higher stomatal sensitivity showed the larger reduction in $g_{\mathrm{s}}$ but minor reduction in $P_{\mathrm{N}}$ than those of L21 scion with their lower stomatal sensitivity. These suggested that the higher $P_{\mathrm{N}}$ in L14 scion seemed to be due to lower nonstomatal limitations.

There was a significant difference in nonstomatal factors between L14 scion and L21 scion under water stress, when they were grafted onto the same rootstock. The $P_{\mathrm{N}} / C_{\mathrm{i}}$ curves showed higher CE and $P_{\max }$ in the L14 scion than that of L21 scion under water stress. Rubisco, a key enzyme of the Calvin Benson cycle, catalyzes the $\mathrm{CO}_{2}$ assimilation by the carboxylation of ribulose-1,5bisphosphate (Spreitzer and Salvucci 2002). The reduced initial Rubisco activity during water stress is not mediated by decreased relative water content, but somehow related to $g_{\text {s }}$ (Flexas et al. 2006). Rootstock-induced increase of both CE and initial Rubisco activity was on account of the increased $g_{\mathrm{s}}$ under water stress. However, the L14 scion had higher CE, initial Rubisco activity, and Rubisco activation state than those of the L21 scion under water stress, when they onto the consistent rootstock genotypes had a lack of difference in $g_{s}$. Previous study found the expression levels of $G m R C A \beta$, encoding Rubisco activase in soybean, determined the initial Rubisco activity (Yin et al. 2010). The expression levels of $G m R C A \beta$ were regulated by the allelic variation in its promoter regions (Chao et al. 2014). Our results suggested that the differences in $\mathrm{CO}_{2}$ assimilation efficiency between L14 scion and L21 scion were probably caused by the genotypic variation.

In addition, the Chl fluorescence measurements were also used to reveal the characteristic of PSII in differently grafted plants under water stress. The parameters of $\mathrm{Y}_{(\mathrm{II})}$, $\mathrm{q}_{\mathrm{P}}$, and ETR are correlated with photochemical processes (Yang et al. 2014), while NPQ reflects the amount of redundant energy from photosynthetic electron transport that was dissipated innocuously as heat energy from PSII antennae (Veres et al. 2006). Previous studies found reductions of $\mathrm{Y}_{(\mathrm{II})}, \mathrm{q}_{\mathrm{P}}$, and ETR, as well as an increase of NPQ in plants in response to water stress (Zlatev et al. 2004, Li et al. 2006, Brestič and Živčák 2013). Similar results were found in the study and showed that the effect of L14 rootstock or scion enhanced the photochemical efficiency and dissipation of unused light energy under water deficit, resulting in an active PSII and consequently in an increased photosynthetic capability.

Conclusions: The drought-tolerant cultivar as the rootstock could maintain greater water absorption capacity under water stress conditions, resulting in more favourable leaf water status and consequently in stronger photosynthetic capacity via both stomatal and nonstomatal factors. Although the photosynthetic capacity of the drought-sensitive scion cultivar was improved by grafting onto drought-tolerant cultivar rootstock, it was still lower than that of the drought-tolerant cultivar scion, which was 
mainly due to the difference between scions in nonstomatal factors. The drought-tolerant cultivar as the scion conferred larger stomatal sensitivity, $\mathrm{CO}_{2}$ assimilation efficiency, and PSII activity. These indicated that not only the greater water absorption capacity via roots, but also the physiological property of leaves conferred to higher photosynthetic capacity and drought resistance in soybean. We suggested that the coordinating improvement between roots and shoots could enhance the photosynthesis, which would be ideally considered for improving drought resistance in soybean.

\section{References}

Blum A.: Drought resistance and its improvement. - In: Plant Breeding for Water-Limited Environments. Pp. 53-152. Springer, New York 2011.

Brestič M., Živčák M.: PSII fluorescence techniques for measurement of drought and high temperature stress signal in crop plants: Protocols and applications. - In: Rout G.R., Das A.B. (ed.): Molecular Stress Physiology of Plants. Pp. 87-131. Springer, New Delhi 2013.

Cai S., Xu D.: [Relationship between the $\mathrm{CO}_{2}$ compensation point and photorespiration in soybean leaves.] - Acta Phytophysiol. Sin. 26: 545-550, 2000. [In Chinese]

Chao M., Yin Z., Hao D. et al:: Variation in Rubisco activase $(R C A \beta)$ gene promoters and expression in soybean [Glycine $\max ($ L.) Merr.]. - J. Exp. Bot. 65: 47-59, 2014.

Comas L.H., Becker S.R., Cruz V.M.V. et al.: Root traits contributing to plant productivity under drought. - Front. Plant Sci. 4: 442, 2013.

Cui X., Dong Y., Gi P. et al.: Relationship between root vigour, photosynthesis and biomass in soybean cultivars during 87 years of genetic improvement in the northern China. Photosynthetica 54: 81-86, 2016.

Egilla J.N., Davies F.T., Boutton T.W.: Drought stress influences leaf water content, photosynthesis, and water-use efficiency of Hibiscus rosa-sinensis at three potassium concentrations. Photosynthetica 43: 135-140, 2005.

Fenta B.A., Beebe S.E., Kunert K.J. et al.: Field phenotyping of soybean roots for drought stress tolerance. - Agronomy 4: 418-435, 2014.

Fenta B.A., Driscoll S.P., Kunert K.J., Foyer C.H.: Characterization of drought-tolerance traits in nodulated soya beans: The importance of maintaining photosynthesis and shoot biomass under drought-induced limitations on nitrogen metabolism. J. Agron. Crop Sci. 198: 92-103, 2012.

Flagella Z., Campanile R.G., Stoppelli M.C. et al.: Drought tolerance of photosynthetic electron transport under $\mathrm{CO}_{2-}$ enriched and normal air in cereal species. - Physiol. Plantarum 104: 753-759, 1998.

Flexas J., Ribas-Carbó M., Bota J. et al.: Decreased Rubisco activity during water stress is not induced by decreased relative water content but related to conditions of low stomatal conductance and chloroplast $\mathrm{CO}_{2}$ concentration. New Phytol. 172: 73-82, 2006.

Gilbert M.E., Zwieniecki M.A., Holbrook N.M.: Independent variation in photosynthetic capacity and stomatal conductance leads to differences in intrinsic water use efficiency in 11 soybean genotypes before and during mild drought. - J. Exp. Bot. 62: 2875-2887, 2011.

He J.X., Wang J., Liang H.G.: Effects of water stress on photochemical function and protein metabolism of photosystem II in wheat leaves. - Physiol. Plantarum 93: 771-777, 1995.
Kao W.Y., Tsai T.T.: Tropic leaf movements, photosynthetic gas exchange, leaf $\delta^{13} \mathrm{C}$ and chlorophyll $a$ fluorescence of three soybean species in response to water availability. - Plant Cell Environ. 21: 1055-1062, 1998.

Kokubun M., Shimada S., Takahashi M.: Flower abortion caused by preanthesis water deficit is not attributed to impairment of pollen in soybean. - Crop Sci. 41: 1517-1521, 2001.

Kumar P., Rouphael Y., Cardarelli M., Colla G.: Vegetable grafting as a tool to improve drought resistance and water use efficiency. - Front. Plant Sci. 8: 1130, 2017.

Li R.H., Guo P.G., Michael B. et al.: Evaluation of chlorophyll content and fluorescence parameters as indicators of drought tolerance in barley. - Agr. Sci. China 5: 751-757, 2006.

Li S., Teng F., Rao D. et al.: Agronomic traits of soybean cultivars released in different decades after grafting recordyield cultivar as rootstock. - Plant Breeding 136: 133-138, $2017 \mathrm{a}$.

Li S., Wang W., Cao Y. et al.: How root traits would be affected by soybean yield improvement? An examination of historical cultivars grafted with record-yield cultivar scion. - Plant Soil 439: 19-30, 2019.

Li S.Y., Teng F., Rao D.M. et al.: Photosynthesis of soybean cultivars released in different decades after grafting onto record-yield cultivars as rootstocks. - Photosynthetica 55: 579-587, $2017 \mathrm{~b}$.

Li T.L., Liu Y.F., Qi H.Y., Bai C.M.: Grafting effects on root activity and amino acid contents in bleeding sap of muskmelon. - Hortic. Environ. Biote. 50: 175-180, 2009.

Liu F., Jensen C.R., Andersen M.N.: Drought stress effect on carbohydrate concentration in soybean leaves and pods during early reproductive development: Its implication in altering pod set. - Field Crop. Res. 86: 1-13, 2004.

Liu F., Jensen C.R., Andersen M.N.: Hydraulic and chemical signals in the control of leaf expansion and stomatal conductance in soybean exposed to drought stress. - Funct. Plant Biol. 30: 65-73, 2003.

Liu S., Li H., Lv X. et al.: Grafting cucumber onto luffa improves drought tolerance by increasing ABA biosynthesis and sensitivity. - Sci. Rep.-UK 6: 20212, 2016.

Marguerit E., Brendel O., Lebon E. et al.: Rootstock control of scion transpiration and its acclimation to water deficit are controlled by different genes. - New Phytol. 194: 416-429, 2012.

Mohsenzadeh S., Malboobi M.A., Razavi K., Farrahi-Aschtiani S.: Physiological and molecular responses of Aeluropus lagopoides (Poaceae) to water deficit. - Environ. Exp. Bot. 56: 314-322, 2006.

Nilsen E.T., Freeman J., Grene R., Tokuhisa J.: A rootstock provides water conservation for a grafted commercial tomato (Solanum lycopersicum L.) line in response to mild-drought conditions: A focus on vegetative growth and photosynthetic parameters. - PLoS ONE 9: e115380, 2014.

Ohashi Y., Nakayama N., Saneoka H., Fujita K.: Effects of drought stress on photosynthetic gas exchange, chlorophyll fluorescence and stem diameter of soybean plants. - Biol. Plantarum 50: 138-141, 2006.

Pantalone V.R., Rebetzke G.J., Burton J.W. et al.: Soybean PI 416937 root system contributes to biomass accumulation in reciprocal grafts. - Agron. J. 91: 840-844, 1999.

Peoples M.B., Faizah A.W., Rerkasem B.: Methods for Evaluating Nitrogen Fixation by Nodulated Legumes in the Field. Pp. 76. ACIAR, Canberra 1989.

Rampino P., Pataleo S., Gerardi C. et al.: Drought stress response in wheat: Physiological and molecular analysis of resistant and sensitive genotypes. - Plant Cell Environ. 29: 2143-2152, 2006. 
Ries L.L., Purcell L.C., Carter T.E. et al.: Physiological traits contributing to differential canopy wilting in soybean under drought. - Crop Sci. 52: 272-281, 2012.

Sánchez-Rodríguez E., del Mar Rubio-Wilhelmi M., Blasco B. et al:: Antioxidant response resides in the shoot in reciprocal grafts of drought-tolerant and drought-sensitive cultivars in tomato under water stress. - Plant Sci. 188-189: 89-96, 2012.

Sánchez-Rodríguez E., Romero L., Ruiz J.M.: Accumulation of free polyamines enhances the antioxidant response in fruits of grafted tomato plants under water stress. - J. Plant Physiol. 190: 72-78, 2016.

Sanders P.L., Markhart A.H.: Interspecific grafts demonstrate root system control of leaf water status in water-stressed Phaseolus. - J. Exp. Bot. 43: 1563-1567, 1992.

Schwarz D., Rouphael Y., Colla G., Venema J.H.: Grafting as a tool to improve tolerance of vegetables to abiotic stresses: thermal stress, water stress and organic pollutants. - Sci. Hortic.-Amsterdam 127: 162-171, 2010.

Serraj R., Bona S., Purcell L.C., Sinclair T.R. Nitrogen accumulation and nodule activity of field-grown 'Jackson' soybean in response to water deficits. - Field Crop. Res. 52: 109-116, 1997.

Shao H.B., Chu L.Y., Jaleel C.A. et al.: Understanding water deficit stress-induced changes in the basic metabolism of higher plants - Biotechnologically and sustainably improving agriculture and the ecoenvironment in arid regions of the globe. - Crit. Rev. Biotechnol. 29: 131-151, 2009.

Spreitzer R.J., Salvucci M.E.: Rubisco: structure, regulatory interactions, and possibilities for a better enzyme. - Annu. Rev. Plant Biol. 53: 449-475, 2002.

Sulpice R., Tschoep H., Von Korff M. et al.: Description and applications of a rapid and sensitive non-radioactive microplate-based assay for maximum and initial activity of
D-ribulose-1,5-bisphosphate carboxylase/oxygenase. - Plant Cell Environ. 30: 1163-1175, 2007.

Tanaka N., Kato M., Tomioka R. et al.: Characteristics of a root hair-less line of Arabidopsis thaliana under physiological stresses. - J. Exp. Bot. 65: 1497-1512, 2014.

Vadez V.: Root hydraulics: The forgotten side of roots in drought adaptation. - Field Crop. Res. 165: 15-24, 2014.

Veres S., Tóth V.R., Láposi R. et al.: Carotenoid composition and photochemical activity of four sandy grassland species. Photosynthetica 44: 255-261, 2006.

Xoconostle-Cazares B., Ramirez-Ortega F.A., Flores-Elenes L. et al.: Drought tolerance in crop plants. - Am. J. Plant Physiol. 5: 241-256, 2010.

Yan C., Wang W., Cao Y. et al.: [Response of physiological characteristics of different drought-tolerant soybean varieties to different rainfall climatic conditions.] - Soybean Sci. 37: 359-368, 2018. [In Chinese]

Yang W., Gao Y., Wu L. et al.: Preconcentration and in-situ photoreduction of trace selenium using $\mathrm{TiO}_{2}$ nanoparticles, followed by its determination by slurry photochemical vapor generation atomic fluorescence spectrometry. - Microchim. Acta 181: 197-204, 2014.

Yin Z., Meng F., Song H. et al.: Expression quantitative trait loci analysis of two genes encoding rubisco activase in soybean. Plant Physiol. 152: 1625-1637, 2010.

Zhang M., Zhai Z., Tian X. et al.: Brassinolide alleviated the adverse effect of water deficits on photosynthesis and the antioxidant of soybean (Glycine max L.). - Plant Growth Regul. 56: 257-264, 2008.

Zlatev Z.S., Yordanov I.T.: Effects of soil drought on photosynthesis and chlorophyll fluorescence in bean plants. - Bulg. J. Plant Physiol. 30: 3-18, 2004.

(C) The authors. This is an open access article distributed under the terms of the Creative Commons BY-NC-ND Licence. 